\title{
SISTEM PAKAR DIAGNOSA OVERHEATING PADA KENDARAAN BERSISTEM PENDINGIN AIR (LIQUID COOLING SYSTEM)
}

\author{
Adika Nur Sandrayanto ${ }^{1}$, Kemal Farouq Mauladi ${ }^{2}$ \\ $\left.{ }^{1}\right)$ Program Studi Teknik Informatika Universitas Islam Lamongan, \\ ${ }^{2,3}$ ) Dosen Fakultas Teknik Prodi Teknik Informatika Universitas Islam Lamongan,
}

Email :dika.symbian@gmail.com,kemalfarouq_mauladi@gmail.com,retzno@gmail.com

\begin{abstract}
Abstrak
Overheating merupakan suatu kondisi dimana temperatur mesin kendaraan melebihi batas normal, kondisi ini dapat diketahui melalui indikator temperatur. Sebagian pemilik kendaraan sering kali mengabaikan fungsi indikator temperatur sehingga tidak mempedulikan seberapa tinggi suhu kendaraan. Hal tersebut dikarenakan pemilik kendaraan tidak tahu temperatur mobil tersebut normal atau tidak. Padahal menjaga temperatur kendaraan tetap normal merupakan hal yang penting, bahkan dapat terjadi kerusakan fatal pada komponen mesin jika kendaraan sampai mengalami overhating. Karena itu sistem ini dibuat untuk menangani masalah overheating kendaraan bersistem pendingin air dengan mencari penyebab dan solusinya. Wawancara pada ahli mesin, ahli radiator dan ahli kelistrikan mobil dilakukan untuk mendapatkan data yang tepat dan akurat mengenai permasalahan overheating. Dari data yang diperoleh maka dibuat sebuah sistem yang dapat digunakan untuk mencari penyebab dan solusi menangani overheating menggunakan metode backward elimination dan certainly factor. Sistem pakar ini memiliki akurasi penentuan masalah hingga $90 \%$.
\end{abstract}

Kata Kunci: overheating, backward elimination, certainly factor, radiator.

\section{Abstract}

Overheating is a condition in which the temperature of the engine of the vehicle exceeds the normal range, this condition can be known through the temperature indicator. Most vehicle owners often ignore the temperature indicator functions so there is no concern for how high the temperature of the vehicle. That is because the owner of the vehicle did not know the car temperature is normal or not. But keeping the temperature remains normal vehicles is crucial, even fatal damage can occur on a component of the engine if the vehicle to experience overheating. Therefore, this system is created to deal with overheating problems with water cooling system of the vehicle looking for causes and solutions. interviews to the expert of the engine, radiator and electricity car are done to get the proper and accurate data regarding the problem of overheating. From data obtained then created a system that can be used to search for causes and solutions concerning the overheating method using backward elimination and certainly factor. Expert system has a problem determination accuracy of up to $90 \%$.

Keyword: overheating, backward elimination, certanly factor, radiator 


\section{PENDAHULUAN}

Sebagian pemilik kendaraan sering kali mengabaikan fungsi indikator temperatur sehingga tidak mempedulikan seberapa tinggi suhu kendaraan. Hal tersebut dikarenakan pemilik kendaraan tidak tahu temperatur mobil tersebut normal atau tidak. Padahal menjaga temperatur kendaraan tetap normal merupakan hal yang penting, bahkan dapat terjadi kerusakan fatal pada komponen mesin jika kendaraan sampai mengalami overhating. Selain itu overheating juga dapat mengakibatkan mesin mati secara tiba-tiba.

Dari permasalahan di atas akan dibuat suatu sistem pakar yang bisa membantu untuk mencari penyebab terjadinya overheating dan memberikan solusi untuk menaganinya. Sistem yang dibuat merupakan sistem pakar berbasis web responsive sehingga dapat diakses dari perangkat mobile dengan berbagai resolusi layar tanpa merusak tampilan aslinya. Sistem paka ini dibuat dengan menggunakan metode backward elimination dan certainly factor.

Dengan adanya sistem tersebut, diharapkan pemilik atau pengendara dapat mengetahui dengan mudah apakah temperatur mesin pada kendaraan tersebut normal atau tidak dan mengetahui apa penyebabnya sehingga permasalahan mobil mogok ditengah perjalanan yang diakibatkan oleh permasalahan overheating bisa berkurang.

Adapun tujuan dari penelitian ini adalah sebagai berikut : a. Untuk mengetahui penyebab dan solusi overheating pada kendaraan yang menggunakan sistem pendingin air.

b. Untuk mengetahui cara pembuatan sistem pakar diagnosa overheating kendaraan yang menggunakan sistem pendingin air

\section{PEMBAHASAN}

Menguraikan hasil analisis kualitatif dan kuantitatif dari penelitian

Temperatur mesin kendaraan merupakan hal penting yang harus diperhatikan. Temperatur mesin yang berlebihan (overheating) atau tidak normal dapat mengganggu performa kendaraan bahkan dapat mengakibatkan kerusakan fatal pada komponen mesin kendaraan.

Ada banyak faktor yang mempengaruhi terjadinya overheating pada kendaraan bersistem pendingin air. Sirkulasi air kurang baik, putaran kipas yang tidak maksimal, kondisi sistem pendingin, permasalahan pada mesin, dan kerusakan beberapa komponen lain, menjadi penyebab paling sering terjadinya overheating kendaraan. Maka bila mendapati suhu mesin kendaraan mulai tidak normal, segeralah perhatikan sejumlah kerja komponen yang berkait dengan sistem pendingin.

\section{Blok Diagram}

Tahapan perancangan sistem ini menggunakan data flow diagram (DFD) level 0 dan level 1 sebagai berikut:

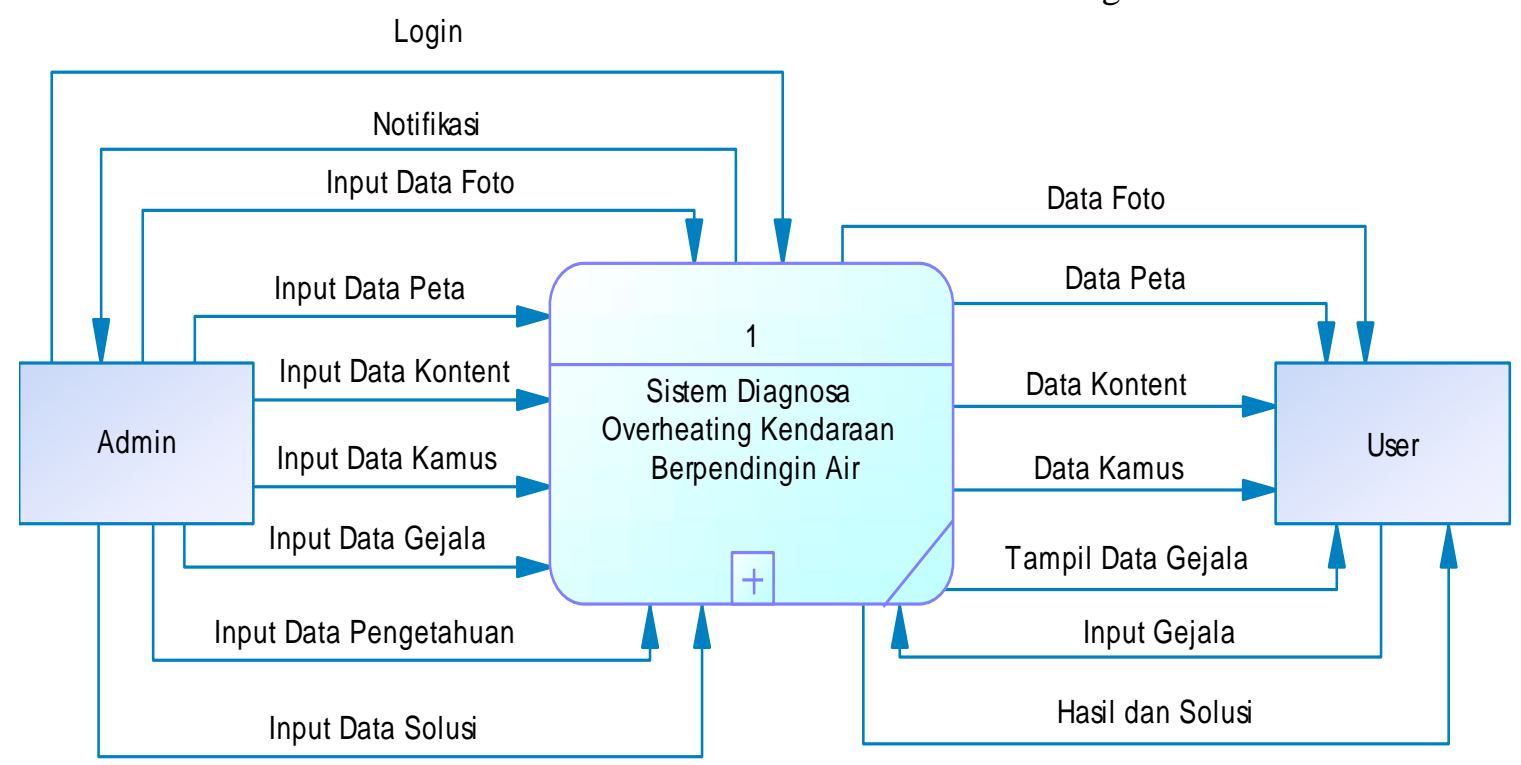

Gambar 1. DFD Level 0 
Keterangan:

DFD level 0 ini adalah gambaran umum dari sistem diagnosa overheating kendaraan berpendingin air. Sistem ini memiliki 2 entity yaitu Administrator dan User. Kedua Entity tersebut berpengaruh pada keberhasilan sistem untuk memberikan hasil diagnosa. Penjelasan pengaruh entity pada sistem adalah sebagai berikut:

a. Admin atau Ahli adalah pihak yang bertugas melakukan input pengetahuan pada sistem. Kemampuan seorang administrator sekaligus sebagai peneliti merupakan faktor utama yang mempengaruhi berhasil atau tidaknya pembuatan sistem tersebut yang mempengaruhi keakuratan sistem dalam memecahkan masalah. Untuk dapat melakukan pengelolaan data berupa input, update dan delete maka admin harus melakukan login.

b. Pengguna atau user juga mempengaruhi hasil dari diagnosa. Kemampuan pemahaman seorang user dalam berinteraksi dengan sistem akan berpengaruh besar terhadap diagnosa yang akan dihasilkan oleh sistem.I

c. Pada sistem pakar diagnosa overheating kendaraan bersistem pendingin air ini, pengguna yang ingin melakukan diagnosa overheating dapat langsung masuk pada menu diagosa tanpa harus melakukan login terlebih dahulu. Namun jika pengguna ingin melakukan pengolahan data maka pengguna harus melakukan login sebagai admin.

Data Flow Diagram Level 1

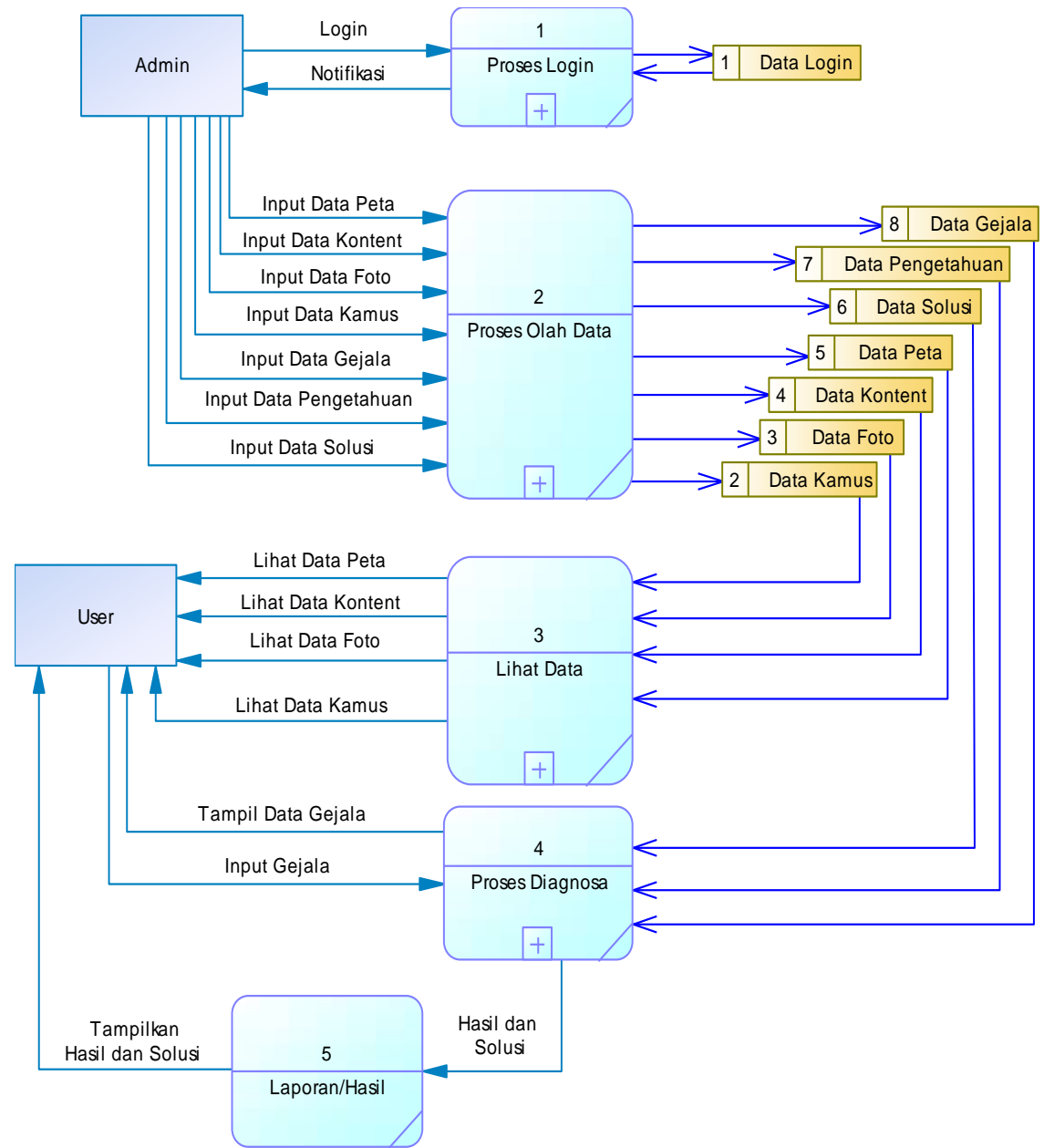

Gambar 2. DFD Level 1 
Keterangan:

a. Pada DFD level 1, proses pertama adalah admin atau ahli melakukan login. Dengan melakukan login sebagai admin, maka akan dapat melakukan pengelolaan data.

b. Proses selanjutnya yaitu melakukan input data. Pada proses ini admin melakukan input data foto, data peta, data konten data kamus, data gejala, data pengetahuan dan data solusi.

c. Selanjutnaya user dapat melihat data peta, data foto, data konten dan data kamus.

d. Proses selanjutnya adalah proses diagnosa, pada proses ini ada 2 tabel yang berperan yaitu tabel gejala dan tabel pengetahuan. Pada proses ini user akan menerima tampilan data gejala harus dijawab, user melakukan input data dengan menjawab pertanyaan, kemudian data akan diolah dalam proses diagnosa ini. Tabel pengetahuan berperan dalam pengolahan data.

e. Kemudian setelah selesai, hasil diagnosa akan diproses dan pengguna akan mendapatkan hasil berupa penyebab overheating dan solusinya.

\section{Uji Coba}

a. Menu Utama

Menu Utama adalah tampilan yang pertama kali muncul ketika pengguna masuk pada sistem

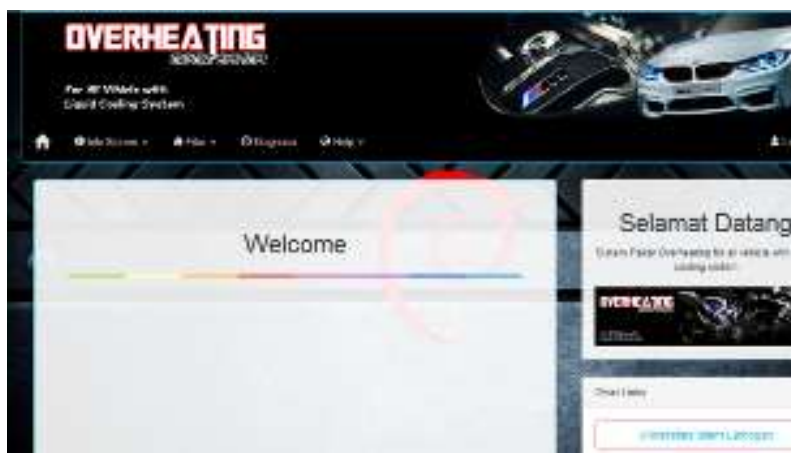

Gambar 3. Tampilan Halaman Utama

b. Menu Login

Menu Login digunakan untuk admin

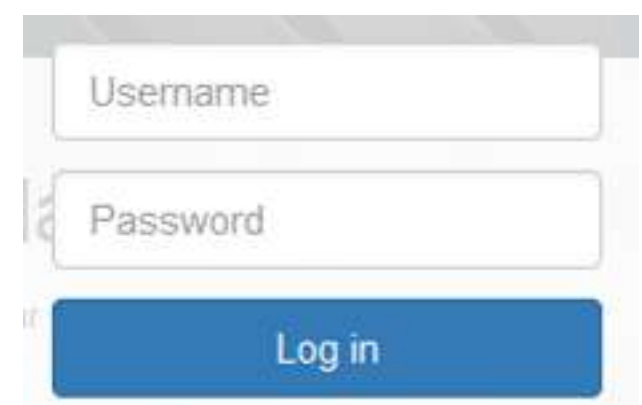

Gambar 4. Tampilan Login

c. Menu Peta

Berisi daftar peta bengkel Radiator yang ada di sekitar kota Lamongan

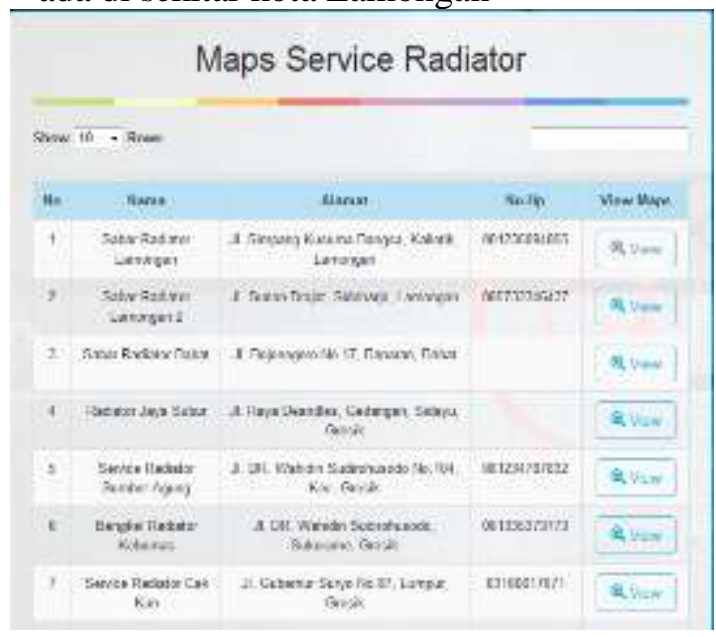

Gambar 5. Tampilan Peta

d. Menu Diagnosa

Untuk melakukan diagnosa dengan metode backward Elimination

\section{Diagnosa Overheating}

Temoeratur ticak nomal, A.r pada radiator berkurang dan air pada tabung cadangar berkirang

Catici:-

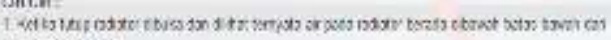
unitutescaty

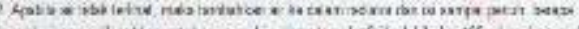

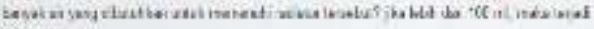
क्weres

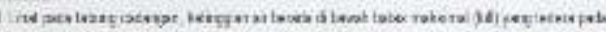

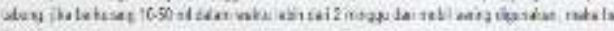
ange

\section{Ya Tidak}

Gambar 6. Tampilan Diagnosa

e. Menu Analisa

Untuk melakukan analisa dengan metode certainly factor 


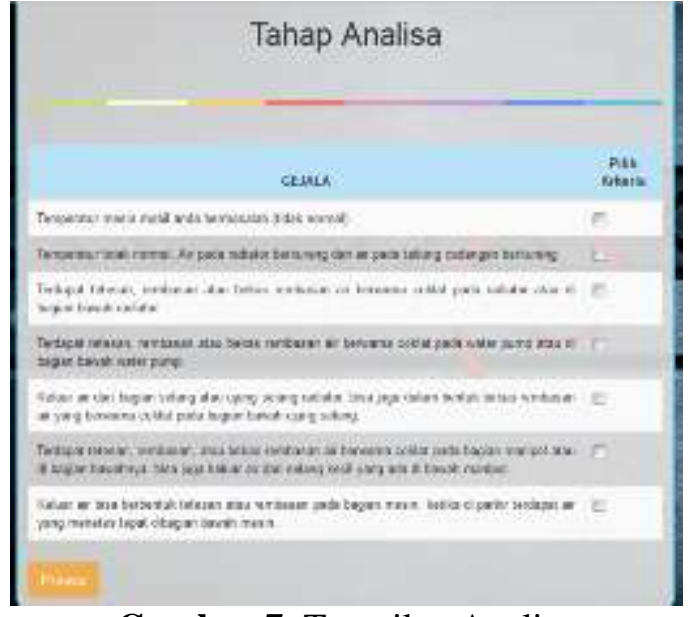

Gambar 7. Tampilan Analisa

f. Tampilan Hasil

Merupakan tampilan hasil dari analisa.

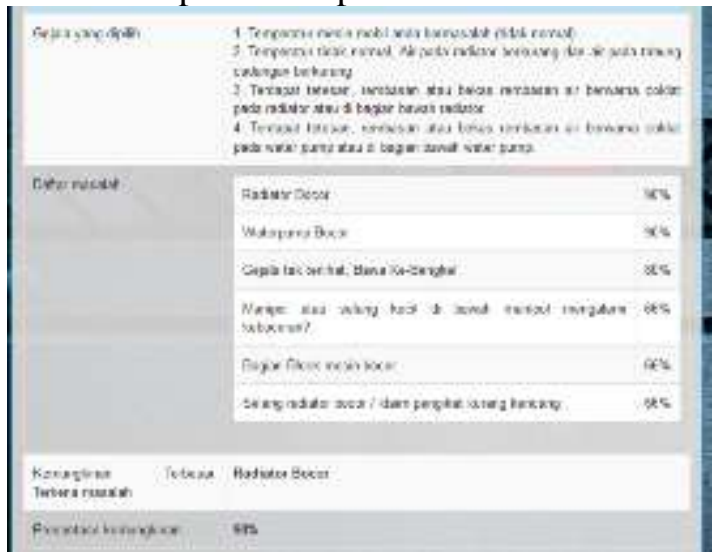

Gambar 8. Tampilan Hasil

\section{KESIMPULAN}

Dari hasil penelitian, analisa dan desain sistem yang telah dilakukan maka diperoleh kesimpulan, Diperoleh data tentang penyebab suhu mesin mobil tidak normal yang akurat. Dan juga diperoleh solusi untuk mengatasi masalah tersebut sehingga telah dihasilkan sebuah sistem pakar untuk mendeteksi kerusakan yang terjadi pada mesin mobil yang menyebabkan temperatur mesin tidak normal beserta solusi untuk menanganinya. Dari hasil pengujian serta analisa penelitian menggunakan metode Backward Elimination dan Certainly Factor maka diperoleh hasil CF (faktor kepastian) hingga 0.9.

\section{PUSTAKA}

Madcoms. 2013. Kupas Tuntas Adobe

Dreamweaver CS6 Dengan Pemrograman

$P H P \& M y S Q L$. CV. Andi Offset.

Yogyakarta.
Saputra, Agus. 2012. Web Trik PHP, HTML5

Dan CSS3. Jasakom. Jakarta.

Sutojo, T. Dkk. 2011. Kecerdasan Buatan. CV. Andi Offset. Yogyakarta.

Toto Haryanto, "Certainly Factor", http://totoharyanto.staff.ipb.ac.id/2011/11/2 5/ certainty-factor-cf/ (diakses pada tanggal 21 Mei 2016 pukul 10.40)

Wawan Yunanto, S.Kom, “Algoritma Backward Chaining pada Rule-Base Expert System"http://ilmukomputer.com/2007/02/ algoritma-backward-chaining-pada-rulebase-expert-system.html, (diakses pada 23/05/2001) 
